\title{
A GRAVIMETRIC METHOD FOR THE DETERMINATION OF RUTHENIUM
}

\author{
By Raleigh Gilchrist
}

ABSTRACT

A gravimetric procedure for the accurate determination of ruthenium by hydrolytic precipitation from chloride solution has been developed. A delicate test for the qualitative detection of small quantities of ruthenium, using thiourea as a reagent, is described.

\section{CONTENTS}

I. Introduction $-P a g$

II. Precipitation by hydrolysis

III. Experiments to determine conditions for complete precipitation of ruthenium by hydrolysis . .

IV. Experiments to determine best conditions for ignition of hydrated ruthenium oxide

997

1000

V. Examination of filtrates from hydrolysis for presence of ruthenium-
1. Development of a green or bluish green color by reaction
with thiourea

V. Examination of filtrates from hydrolysis for presence of ruthenium-
1. Development of a green or bluish green color by reaction
with thiourea

2. Development of a pink or rose color by reaction with sodium thiosulphate.....

VI. Precipitation of ruthenium from solutions containing potassium chloride

1000

1000

1001

1001

1002

1002

1003

1003

1003

1003

1. Precipitation

1003

\section{INTRODUCTION}

In the analysis of a material containing the platinum metals, such as crude platinum, osmiridium, etc., it has been the customary procedure, since the work of Deville and Stas, ${ }^{1}$ to separate ruthenium by distillation with chlorine from an alkaline hypochlorite solution. The ruthenium tetroxide set free is absorbed either in a solution of hydrochloric acid containing some alcohol, or in a solution of an alkali hydroxide, likewise containing some alcohol.

Quite recently the separation of ruthenium by distillation with perchloric acid ${ }^{2}$ has been proposed in a scheme of qualitative analysis. Although this separation is apparently very satisfactory

1 H. Ste-C. Deville and J. S. Stas, Procès-verbaux, Comité International des poids et mesures, p. 194; 1877.

2 Noyes and Bray, Qualitative Analysis for the Rare Elements. The MacMillan Co.; 1927. 
for the purpose intended, a strictly quantitative study of it has not been made. This is true also of the separation by distillation with chlorine. Before a study of such separations could be made it was necessary to develop an accurate method for the quantitative recovery of ruthenium from solutions used as absorbents for ruthenium tetroxide. The experiments described in this paper were designed to develop such a method.

Of the methods previously proposed for the determination of ruthenium in the absorbent solutions none has been entirely satisfactory. Deville and Stas simply evaporated in a crucible the entire acid solution, containing the ruthenium as chloride, reduced the dried chloride thus obtained, washed the residue with water to remove any soluble salts, and weighed the ruthenium as metal. This procedure is somewhat troublesome at best and is clearly impracticable if large amounts of alkali halides are present.

Howe and Mercer ${ }^{3}$ preferred to use a dilute solution of potassium hydroxide containing some alcohol as the reagent to absorb the ruthenium tetroxide separated by distillation. These authors precipitated the ruthenium as an oxide from this alkaline solution by gentle warming. They state that here the success of their work from the standpoint of quantitative determination ceased; that no satisfactory method could be found to collect this oxide for weighing, as it was impossible to free it from the alkali present. The oxide so obtained became colloidal after a single washing. They moistened the partially washed and dried precipitate with a few drops of hydrochloric acid, burned it, reduced the residue in hydrogen, washed the metal obtained with boiling water, and reduced again in hydrogen. The conclusion was that the method was too complicated for quantitative work.

Recently volumetric methods have been introduced, more particularly in the investigation of the constitution of the complex ruthenium salts, and especially with reference to the state of valency possessed by the ruthenium. A volumetric method in which iodine, liberated from potassium iodide through oxidation by ruthenium, is titrated with sodium thiosulphate has been employed by Krauss, ${ }^{4}$ Krauss and Kükenthal, ${ }^{5}$ Charronat, ${ }^{6}$ Gall and Lehmann, ${ }^{7}$ and others.

Howe, ${ }^{8}$ failing to obtain satisfactory analytical results with potassium iodide, investigated a volumetric method using stannous chlorride. Howe sums up his work on the titration with stannous chloride by saying that it should be noted that in almost every case the amount of stannous chloride required for reduction was somewhat lower than that called for by theory. For this reason, he says, the method can not be recommended for the accurate determination of ruthenium, but it does afford a ready method for the approximate evaluation of ruthenium solutions and for the determination of ruthenium when only a small amount is present.

\footnotetext{
3 Jas. L. Howe and F. N. Mercer, J. Am. Chem. Soc., 47, p. 2926; 1925.

4 F. Krauss, Z. anorg allgem. Chem., 117, p. 111; 1921 .

$\checkmark \mathrm{F}$. Krauss and H. Kükenthal, Z. anorg. allgem. Chem., 136, p. 62; 1924.

6 A. Charronat, Compt. rend., 180, p. 1271; 1925.

7 H. Gall and G. Lehmann, Ber., 59, p. 2856; 1926.

8 Howe, J. Am. Chem. Soc., 49, p. 2381; 1927.
} 


\section{PRECIPITATION BY HYDROLYSIS}

The work of Ruff and Bornemann ${ }^{9}$ on the determination of osmium suggested the possibility of a somewhat similar method for ruthenium. Ruff and Bornemann precipitated hydrated osmium dioxide by neutralizing an alkaline osmate solution with sulphuric acid.

A few experiments were made with ruthenium, following Ruff and Bornemann's procedure for osmium. Six $10 \mathrm{ml}$ portions of a solution of ruthenium chloride, containing about $0.001 \mathrm{~g}$ of ruthenium per milliliter, were made strongly alkaline with sodium hydroxide and allowed to stand on the steam bath for about one hour. The excess alkali was then neutralized with $2 N$ sulphuric acid, using phenolphthalein as indicator. The neutral solutions were allowed to remain on the steam bath for an additional hour before filtering. The precipitates were washed with a hot 1 per cent solution of ammonium sulphate. The quantities of ruthenium recovered were 0.0107 , $0.0111,0.0107,0.0107,0.0107$, and $0.0106 \mathrm{~g}$, the average being $0.0108 \mathrm{~g}$. The quantities of ruthenium recovered from four $10 \mathrm{ml}$ portions of the same solution, which has been evaporated in crucibles and ignited in hydrogen to metal, were 0.0104, 0.0106, 0.0105, and $0.0105 \mathrm{~g}$, the average being $0.0105 \mathrm{~g}$.

The results are seen to be slightly higher than those obtained by simple evaporation and reduction. Some silica may have been carried down with the precipitated ruthenium, as was observed by Ruff and Bornemann in the case of osmium. It appeared that such contamination might be avoided, as well as that due to the adsorption of alkali, if the neutralization of the ruthenium solution were approached from the acid side. Accordingly, two $10 \mathrm{ml}$ portions of the ruthenium chloride solution were diluted to about $100 \mathrm{ml}$ each, heated to boiling and neutralized with a solution of sodium bicarbonate. The solutions were boiled about 10 minutes. The quantities of ruthenium recovered were 0.0104 and $0.0104 \mathrm{~g}$. It was observed that as the solution approached neutrality a well-coagulated precipitate suddenly appeared, leaving a clear supernatant liquid which was acid to methyl red indicator. Additional bicarbonate and longer boiling produced no further precipitation of ruthenium.

\section{EXPERIMENTS TO DETERMINE CONDITIONS FOR COM- PLETE PRECIPITATION OF RUTHENIUM BY HYDROIYSIS}

In order to avoid errors due to volumetric measurements, weighed portions of the compound, ammonium chlororuthenate, were used in subsequent experiments.

Three preparations of this salt were made. That used in the experiments reported in Table 1 was obtained. as the final product of the refining of a large quantity of ruthenium. It was the salt which was precipitated by adding a saturated solution of ammonium chloride to the solution of ruthenium chloride produced by dissolving ruthenium tetroxide in hydrochloric acid. The second preparation, used in the experiments reported in Tables 2, 3, and 4, was made from ruthenium sponge obtained by igniting a portion of the salt, mentioned above, in hydrogen. No impurities were detected in this spongy 
metal by spectrographic examination. This sponge was dissolved in a mixture of sodium hydroxide and sodium hypochlorite, according to the directions of Howe and Mercer, ${ }^{10}$ and the ruthenium tetroxide distilled into $6 \mathrm{~N}$ hydrochloric acid. The resulting solution was evaporated, the sirupy residue redissolved in $6 \mathrm{~N}$ hydrochloric acid, and the filtered solution saturated with chlorine. The relatively insoluble ammonium chlororuthenate, precipitated by the addition of a saturated solution of ammonium chloride, was collected on a hardened filter in a Gooch crucible and washed with 95 per cent alcohol until the washings were colorless. The third preparation, used in the experiments reported in Tables 5 and 6 , was made by recrystallizing a portion of the first preparation from a solution containing 2 per cent of hydrochloric acid. No attempt was made to prepare compounds of definite composition. Each preparation was dried over phosphorous pentoxide in a desiccator, then thoroughly mixed by grinding in an agate mortar.

A number of experiments were made to determine the $\mathrm{pH}$ of the solutions in which the ruthenium was apparently completely precipitated on boiling with sodium bicarbonate. The ruthenium content of the salt used in the first set of experiments, determined by igniting four portions in hydrogen, ranged from 30.89 to 30.92 per cent, average 30.90 per cent. The ruthenium content of this same salt in the second set, after it had remained a greater length of time in the desiccator, was 30.96 per cent, the individual determinations being 30.97 , 30.95 , and 30.97 per cent.

Additional samples, simultaneously taken, were each dissolved in about $150 \mathrm{ml}$ of water. The resulting solutions were boiled for about five minutes. A 10 per cent solution of sodium bicarbonate was added dropwise until the colloidal precipitates, which first formed, coagulated and settled. The solutions were then boiled 10 minutes longer and filtered. The filtrates were removed and the filters and precipitates washed with a hot 1 per cent solution of ammonium sulphate until the chloride ion could no longer be detected in the wash waters. The $\mathrm{pH}$ of each filtrate, without washings, was determined by the comparison of approximately $10 \mathrm{ml}$ portions with solutions of known $\mathrm{pH}$, using brom cresol purple as indicator. The wash waters, together with unused portions of the filtrates, were evaporated and tested for ruthenium as described in a later section of this paper. No ruthenium was detected in these filtrates and washings.

The filters and precipitates were dried and ignited. The tendency of the precipitates to deflagrate had been observed during the very first experiments. In one instance the deflagration amounted to an explosion which shattered the porcelain crucible and bent the wire triangle on which it rested. The oxidized residues from the ignition of the precipitates were reduced to metal by ignition in hydrogen and weighed.

To determine if there was a significant loss of ruthenium on ignition in air, $0.1094 \mathrm{~g}$ of ruthenium sponge was heated in an open crucible with the full heat of the Tirrill burner for three periods of 20 minutes each. At the end of each period the oxidized material was ignited and cooled in hydrogen. The weight obtained in each instance was 
identical with the original weight. In all determinations made throughout this work, both by direct ignition of the salt in hydrogen and by hydrolysis, the weights reported are those obtained after the second ignition period and corrected for the filter ash. This correction amounted to a deduction of $0.0001 \mathrm{~g}$, and was determined from blank runs.

The recoveries in experiments Nos. 11 and 12 are low because a small amount of the precipitate could not be removed from the walls of the beakers. This error is entirely avoided if unetched glassware is used.

The results of the experiments are given in Table 1.

TABLE 1.-Determination of the $p H$ value of the solution in which ruthenium has been completely precipitated by hydrolysis

[Ru content: Series I, 30.90 per cent; Series II, 30.96 per cent]

SERIES I

\begin{tabular}{|c|c|c|c|c|c|}
\hline No. & Salt taken & Ru present & $\begin{array}{l}\text { Ru recov- } \\
\text { ered }\end{array}$ & Error & $\underset{\text { trate }}{\mathrm{pH} \text { of fil- }}$ \\
\hline $1{ }^{9} 10^{2}$ & $\begin{array}{l}0 \\
0.3529 \\
.3516 \\
.3496 \\
.3505\end{array}$ & $\begin{array}{l}g \\
0.1091 \\
.1087 \\
.1081 \\
.1083\end{array}$ & $\begin{array}{l}g \\
0.1091 \\
.1087 \\
.1079 \\
.1080\end{array}$ & $\begin{array}{r}g \\
0.0000 \\
.0000 \\
-.0002 \\
-.0003\end{array}$ & $\begin{array}{l}6.0 \\
6.4 \\
6.4 \\
6.3\end{array}$ \\
\hline
\end{tabular}

SERIES II

\begin{tabular}{|c|c|c|c|c|c|}
\hline $\begin{array}{l}16 \\
16 \\
18 \\
18 \\
18\end{array}$ & $\begin{array}{r}0.3975 \\
.4137 \\
.4495 \\
.4622 \\
.4270\end{array}$ & $\begin{array}{r}0.1231 \\
.1281 \\
.1392 \\
.1431 \\
.1322\end{array}$ & $\begin{array}{r}0.1229 \\
.1281 \\
.1391 \\
.1431 \\
.1322\end{array}$ & $\begin{array}{r}-0.0002 \\
-.0000 \\
-.0001 \\
.0000 \\
.0000\end{array}$ & $\begin{array}{l}6.2 \\
6.4 \\
6.0 \\
6.3 \\
6.3\end{array}$ \\
\hline
\end{tabular}

\section{EXPERIMENTS TO DETERMINE BEST CONDITIONS FOR IGNITION OF HYDRATED RUTHENIUM OXIDE}

It was found early in the experimental work that great care had to be taken to prevent mechanical loss of ruthenium when the hydrated oxide and the filters were ignited. This loss occurred when the filters were charred. Deville and Stas ${ }^{11}$ had experienced the same difficulty with the ignition of hydrated iridium oxide. Ruff and Bornemann ${ }^{12}$ encountered similar trouble with hydrated osmium dioxide, obtained by hydrolysis, and attributed the deflagration which occurred to the splitting off of the water as the compound was converted to the anhydrous form.

It was thought that concentrated sulphuric acid present with the dried filters would possibly extract the water from the hydrated ruthenium oxide and in this way prevent deflagration. The results with sulphuric acid, however, were not particularly satisfactory. Deflagration was prevented in some instances, but the results were high, owing probably to the incomplete removal of carbonaceous matter rather than to the retention of sulphur, as no significant amount of sulphur could be found in the metal residues. In other instances deflagration, with simultaneous loss of ruthenium, occurred anyway. 
Two experiments were made in which the precipitates and filters were merely washed with hot water. On charring the filters these precipitates decrepitated badly.

Precipitates which had been washed with a 1 per cent solution of ammonium sulphate or of ammonium chloride either did not deflagrate or only crackled slightly, with no loss of ruthenium, if the filters were charred slowly. It was observed that if the filters contained a small quantity of either of the salts named they would nearly always char completely when once they began to smoke, without the addition of further heat. Once the filters were charred there was no further danger of deflagration, and the subsequent ignition could be conducted without special precaution.

Since the presence of a small quantity of ammonium sulphate or of ammonium chloride appeared to minimize the danger of loss, somewhat stronger solutions of these salts were tried. These stronger solutions were placed on the filters after complete washing had been accomplished with a hot 1 per cent solution of the particular salt in question. A 5 per cent solution of ammonium sulphate used as a final wash to impregnate the filters, prevented deflagration entirely, even when the filters were charred as in ordinary analytical practice, but the results were somewhat high, similar to those obtained with sulphuric acid. A 5 per cent solution of ammonium chloride likewise prevented deflagration, but the results were low, possibly because of volatilization of some ruthenium as chloride.

A 2.5 per cent solution of either ammonium sulphate or ammonium chloride equally prevented deflagration, even though no special care was taken during the charring, and apparently caused no errors.

The hydrated ruthenium oxide was precipitated from boiling solutions by adding a 10 per cent solution of sodium bicarbonate as previously described, the end point being determined by the presence in the solution of brom cresol purple indicator. The carbonate was added until the color of the brom cresol purple changed from yellowish to faint purple. This change occurs at a $\mathrm{pH}$ value of about 6.0. The solutions were boiled 5 to 6 minutes to insure complete precipitation, filtered immediately, and the filters and precipitates washed thoroughly with a hot 1 per cent solution of either ammonium sulphate or of ammonium chloride. Stronger solutions of these salts were then applied as indicated in the following tables. No ruthenium was detected in the filtrates from these precipitations by tests described in the following section of this paper.

The ruthenium salts used were the second and third preparations previously described. The ruthenium content of Preparation II, obtained by direct ignition of 12 portions taken at random from among the samples weighed, ranged from 30.40 to 30.44 per cent and averaged 30.42 per cent. The ruthenium content of Preparation III, the recrystallized salt, obtained by direct ignition of four portions in hydrogen, ranged from 31.22 to 31.26 per cent and averaged 31.24 per cent.

The results of the experiments in which hot water was used for washing and in which sulphuric acid was used to char the filters are given in Table 2. 
TABLE 2.-Effect of washing with water and of charring with $\mathrm{H}_{2} \mathrm{SO}_{4}$

\begin{tabular}{|c|c|c|c|c|c|}
\hline No. & $\begin{array}{l}\text { Salt taken } \\
30.42 \text { per } \\
\text { cent Ru }\end{array}$ & Ru present & $\begin{array}{l}\mathrm{Ru} \text { recov- } \\
\text { ered }\end{array}$ & Error & Remarks \\
\hline 6 & $\begin{array}{l}g \\
0.4524 \\
.4080\end{array}$ & $\begin{array}{l}g \\
0.1376 \\
.1241\end{array}$ & $\begin{array}{l}g \\
0.1324 \\
.1239\end{array}$ & $\begin{array}{r}g \\
-0.0052 \\
-.0002\end{array}$ & Washed with hot water; loss by deflagration. \\
\hline 90 & $\begin{array}{l}.4408 \\
.4599\end{array}$ & .1341 & $\begin{array}{l}.1347 \\
.1402\end{array}$ & $\begin{array}{l}+.0006 \\
+.0003\end{array}$ & $\left\{\begin{array}{l}\text { Washed with hot } 1 \text { per cent }\left(\mathrm{NH}_{4}\right)_{2} \mathrm{SO}_{4} \text {; charred } \\
\text { with } \mathrm{H}_{2} \mathrm{SO}_{4} ; \text { probably incomplete removal of } \\
\text { carbon; no deflagration. }\end{array}\right.$ \\
\hline $11 \ldots$ & $\begin{array}{l}.4497 \\
.4383\end{array}$ & $\begin{array}{l}.1368 \\
.1333\end{array}$ & $\begin{array}{l}.1333 \\
.1330\end{array}$ & $\begin{array}{l}-.0035 \\
-.0003\end{array}$ & $\begin{array}{l}\text { Washed with hot water; charred with } \mathrm{H}_{2} \mathrm{SO}_{4} \text {; } \\
\text { loss by deflagration. }\end{array}$ \\
\hline
\end{tabular}

The results of the experiments in which a hot 1 per cent solution of ammonium sulphate and of ammonium chloride were used for washing and in which the filters were carefully charred are given in Table 3.

TABLE 3.-Effect of careful charring by heat

\begin{tabular}{|c|c|c|c|c|c|}
\hline No. & $\begin{array}{l}\text { Salt taken } \\
30.42 \text { per } \\
\text { cent Ru }\end{array}$ & Ru present & $\begin{array}{l}\text { Ru recov- } \\
\text { ered }\end{array}$ & Error & Remarks \\
\hline 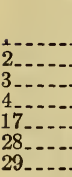 & $\begin{array}{l}g \\
0.4202 \\
.4303 \\
.5593 \\
.5187 \\
.4790 \\
.3601 \\
.3626\end{array}$ & $\begin{array}{l}g \\
0.1278 \\
.1309 \\
.1701 \\
.1578 \\
.1457 \\
.1095 \\
.1103\end{array}$ & $\begin{array}{l}g \\
0.1279 \\
.1309 \\
.1702 \\
.1578 \\
.1457 \\
.1097 \\
.1103\end{array}$ & $\begin{array}{r}g \\
+0.0001 \\
.0000 \\
+.0001 \\
.0000 \\
.0000 \\
+.0002 \\
.0000\end{array}$ & $\begin{array}{l}\text { Washed with hot } 1 \text { per cent }\left(\mathrm{NH}_{4}\right)_{2} \mathrm{SO}_{4} \text {; care- } \\
\text { ful charring by heat; no deflagration. } \\
\text { Washed with hot } 1 \text { per cent } \mathrm{NH}_{4} \mathrm{Cl} \text {; careful } \\
\text { charring by heat; no deflagration. }\end{array}$ \\
\hline
\end{tabular}

The results of the experiments in which 5 per cent solutions of ammonium sulphate and of ammonium chloride were used are given in Table 4.

TABLE 4.-Prevention of deflagration by presence of ammonium salts

\begin{tabular}{|c|c|c|c|c|c|}
\hline No. & $\begin{array}{l}\text { Salt taken } \\
30.42 \text { per } \\
\text { cent } \mathrm{Ru}\end{array}$ & Ru present & $\begin{array}{l}\text { Ru recov- } \\
\text { ered }\end{array}$ & Error & Remarks \\
\hline $\begin{array}{l}13 \ldots \\
15 \\
18 \\
19 \\
-\ldots\end{array}$ & $\begin{array}{l}g \\
0.5007 \\
.5325 \\
.4337 \\
.4453\end{array}$ & $\begin{array}{l}g \\
0.1523 \\
.1620 \\
.1319 \\
.1355\end{array}$ & $\begin{array}{l}g \\
0.1527 \\
.1623 \\
.1322 \\
.1356\end{array}$ & $\begin{aligned} & g \\
+ & 0.0004 \\
+ & .0003 \\
+ & .0003 \\
+ & .0001\end{aligned}$ & $\left\{\begin{array}{l}\text { Washed with hot } 1 \text { per cent }\left(\mathrm{NH}_{4}\right)_{2} \mathrm{SO}_{4} ; \text { final } \\
\text { wash with } 5 \text { per cent }\left(\mathrm{NH}_{4}\right)_{2} \mathrm{SO}_{4} ; \text { no special } \\
\text { precaution taken in charring; no deflagration. }\end{array}\right.$ \\
\hline $\begin{array}{l}26 \ldots \\
27 \ldots\end{array}$ & $\begin{array}{l}.3379 \\
.3955\end{array}$ & $\begin{array}{l}.1028 \\
.1203\end{array}$ & $\begin{array}{l}.1023 \\
.1197\end{array}$ & $\begin{array}{l}-.0005 \\
-.0006\end{array}$ & $\left\{\begin{array}{l}\text { Washed with hot } 1 \text { per cent } \mathrm{NH}_{4} \mathrm{Cl} \text {; final wash } \\
\text { with } 5 \text { per cent } \mathrm{NH}_{4} \mathrm{Cl} \text {; no special precaution } \\
\text { taken in charring; no deflagration; possibly } \\
\text { slight volatilization as chloride. }\end{array}\right.$ \\
\hline
\end{tabular}

The results of the experiments in which 2.5 per cent solutions of ammonium sulphate and of ammonium chloride were used, with no special precaution taken to char the filters, are given in Table 5. The results of two experiments with 1 per cent ammonium sulphate in which the filters were carefully charred are likewise included. 
TABLE 5.-Best conditions for ignition of ruthenium precipitate

\begin{tabular}{|c|c|c|c|c|c|}
\hline No. & $\begin{array}{l}\text { Salt taken } \\
31.24 \text { per } \\
\text { cent Ru }\end{array}$ & Ru present & $\begin{array}{l}\text { Ru recov- } \\
\text { ered }\end{array}$ & Error & Remarks \\
\hline $\begin{array}{l}2 \ldots \ldots \\
3 \ldots\end{array}$ & $\begin{array}{l}g \\
0.2722 \\
.3384\end{array}$ & $\begin{array}{l}g \\
0.0850 \\
.1057\end{array}$ & $\begin{array}{l}g \\
0.0850 \\
.1057\end{array}$ & $\begin{array}{l}g \\
0.0000 \\
.0000\end{array}$ & \multirow{3}{*}{$\begin{array}{l}\text { Washed with hot } 1 \text { per cent }\left(\mathrm{NH}_{4}\right)_{2} \mathrm{SO}_{4} \text {; care- } \\
\text { ful charring; no deflagration } \\
\text { Washed with hot } 1 \text { per cent }\left(\mathrm{NH}_{4}\right)_{2} \mathrm{SO}_{4} \text {; final } \\
\text { wash with } 2.5 \text { per cent }\left(\mathrm{NH}_{4}\right)_{2} \mathrm{SO}_{4} ; \text { no special } \\
\text { precaution taken in charring; no deflagration. } \\
\text { Washed with hot } 1 \text { per cent } \mathrm{NH}_{4} \mathrm{Cl} \text {; final wash } \\
\text { with } 2.5 \text { per cent } \mathrm{NH}_{4} \mathrm{Cl} \text {; no } \mathrm{Special} \text { precau- } \\
\text { tion taken in charring; no deflagration. }\end{array}$} \\
\hline $41 \ldots$ & $\begin{array}{r}.4562 \\
.5329\end{array}$ & $\begin{array}{r}.1425 \\
.1665\end{array}$ & $\begin{array}{l}.1426 \\
.1666\end{array}$ & $\begin{array}{r}+.0001 \\
+.0001\end{array}$ & \\
\hline $\begin{array}{l}40 \ldots \\
43 \ldots\end{array}$ & $\begin{array}{r}4891 \\
.5001\end{array}$ & $\begin{array}{l}.1528 \\
.1562\end{array}$ & $\begin{array}{l}.1527 \\
.1561\end{array}$ & $\begin{array}{l}-.0001 \\
-.0001\end{array}$ & \\
\hline
\end{tabular}

\section{EXAMINATION OF FILTRATES FROM HYDROLYSIS FOR PRESENCE OF RUTHENIUM}

All of the filtrates in the foregoing experiments were carefully examined for the presence of ruthenium. The tests which were used were made as follows:

\section{DEVELOPMENT OF A GREEN OR BLUISH-GREEN COLOR BY REACTION WITH THIOUREA}

Chugaev, ${ }^{13}$ in his researches on osmium compounds, discovered a reaction which serves as a delicate test for osmium. He found that when a solution containing osmium tetroxide or potassium chloroösmate, acidified with a few drops of hydrochloric acid, is heated with thiourea $\left(\mathrm{CS}\left(\mathrm{NH}_{2}\right)_{2}\right)$ for a few minutes a deep red or rose color develops. The limit of sensitivity, according to Chugaev, appears to be 1 part in 100,000 parts of solution.

It was observed in this laboratory that thiourea also develops a color with ruthenium solutions under conditions similar to those specified by Chugaev for osmium. The color with ruthenium is green or bluish-green, depending upon the concentration of the ruthenium. The limit of sensitivity appears to be the same as that for osmium. The test becomes uncertain, however, if the ruthenium solution has been treated with nitric acid or with aqua regia.

\section{DEVELOPMENT OF A PINK OR ROSE COLOR BY REACTION WITH SODIUM THIOSULPHATE}

This delicate test was discovered by C. Lea ${ }_{1}^{14}$ who found that when an ammoniacal solution of ruthenium chloride is heated for a few minutes with sodium thiosulphate $\left(\mathrm{Na}_{2} \mathrm{~S}_{2} \mathrm{O}_{3}\right)$, a permanent pink or rose color develops, depending upon the concentration of the ruthenium. The limit of sensitivity of this test likewise appears to be 1 part in 100,000 parts of solution. In using this test it was observed that previous treatment of the solution with nitric acid or with aqua regia had no effect upon the development of the color.

The filtrates and wash waters from the experiments reported in Table 1 were evaporated to dryness, moistened with a few drops of hydrochloric acid, diluted to $5 \mathrm{ml}$, and heated with a few crystals of

\footnotetext{
${ }^{13}$ L. Chugaev, Compt. rend., 167, p. 235; 1918.

14 Cited by William Crookes, Select Methods in Chemical Analysis (Longmans, Green \& Co.), p. 463;
} 
thiourea. No green color was observed. Solutions containing 0.0001 $\mathrm{g}$ of ruthenium were simultaneously tested. These solutions did develop a distinct color.

The filtrates and wash waters from the experiments reported in Tables 2, 3, 4, and 5 were evaporated to dryness and the brom cresol purple indicator present destroyed by evaporation with concentrated nitric acid. The nitric acid was destroyed by repeated evaporation with concentrated hydrochloric acid before testing with thiosulphate. No pink color was detected in the solutions of the evaporated filtrates. Solutions containing $0.0001 \mathrm{~g}$ of ruthenium were similarly treated and did develop the characteristic pink color.

\section{PRECIPITATION OF RUTHENIUM FROM SOLUTIONS CONTAINING POTASSIUM CHLORIDE}

A few experiments were made to ascertain whether the presence of alkali chlorides would cause any error in the determination of ruthenium by hydrolysis.

The determinations were made as has been previously described, care being taken to wash the filters and precipitates until no chloride ion could be detected in the wash waters. The filters and precipitates were finally washed four to five times with a 2.5 per cent solution of ammonium sulphate to prevent deflagration on ignition. In experiments Nos. 1 and 2 the precipitates were redissolved in 6 $N$ hydrochloric acid after they had been washed only partially. These solutions, freed from paper pulp, were evaporated to eliminate the excess of acid, diluted to a volume of $150 \mathrm{ml}$, and the ruthenium reprecipitated.

The details of the experiments are condensed in Table 6 .

TABLE 6.-Determination of ruthenium by hydrolysis in presence of potassium chloride

\begin{tabular}{|c|c|c|c|c|c|}
\hline No. & Salt taken & Ru present & $\begin{array}{l}\text { Ru re- } \\
\text { covered }\end{array}$ & Error & Remariks \\
\hline $4 .$. & $\begin{array}{c}g \\
0.4546 \\
.5228 \\
.4407 \\
.3461 \\
.6110\end{array}$ & $\begin{array}{c}g \\
0.1420 \\
.11633 \\
.1377 \\
.1081 \\
.1891\end{array}$ & $\begin{array}{c}g \\
0.1420 \\
.1631 \\
.1377 \\
.1082 \\
.1891\end{array}$ & $\begin{array}{r}g \\
0.0000 \\
-.0002 \\
.0000 \\
+.0001 \\
.0000\end{array}$ & 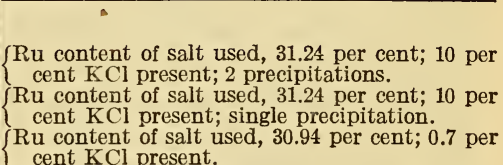 \\
\hline
\end{tabular}

NOTE.-All 5 of the metal residues were leached with hot water. There was no change in weight, except in experiments Nos. 3 and 4 , each of which lost $0.0001 \mathrm{~g}$.

\section{DETERMINATION OF RUTHENIUM IN ALKALINE SOLUTIONS}

As stated in the introduction to this paper, an alkali hydroxide may be used to absorb the ruthenium tetroxide set free by distillation. Two experiments were made to ascertain whether any error in the determination was introduced by having made the solution of ruthenium alkaline.

Two $10 \mathrm{ml}$ portions of a solution of ruthenium chloride, equivalent to $0.0105 \mathrm{~g}$ of ruthenium, were each made strongly alkaline with a freshly prepared solution of sodium hydroxide. The solutions were 
boiled gently for about three minutes, then cooled and acidified with a large excess of hydrochloric acid. The solutions were evaporated to dryness, diluted to a volume of $150 \mathrm{ml}$ with water and the ruthenium precipitated by hydrolysis. The quantities of ruthenium recovered were 0.0104 and $0.0105 \mathrm{~g}$.

\section{BEHAVIOR OF RUTHENIUM WHEN PRESENT AS A NITROSOCHLORIDE}

In the preceding experiments the ruthenium was present as the chloride or as ammonium chlororuthenate. From solutions of such compounds the complete precipitation of ruthenium by hydrolysis is easily accomplished. If the solution of ruthenium chloride has been evaporated with considerable alcohol, thus causing the reduction of the ruthenium to the tervalent stage, ruthenium can be quantitatively precipitated under the conditions described, but the precipitate is somewhat slow in settling and, in general, is not as easy to handle as the quadrivalent compound.

A few experiments were made with solutions in which the ruthenium was present, partly if not entirely, as nitrosochloride $\left(\mathrm{RuCl}_{3} \mathrm{NO}\right)$. This type of compound results when solutions of ruthenium are subjected to a somewhat prolonged treatment with nitric acid or with aqua regia and forms an important class of ruthenium compounds. It was found that solutions containing ruthenium as nitrosochloride yielded only a slight precipitate which appeared to have a tan color rather than the black usually observed.

Several different treatments were tried, qualitatively, in an attempt to remove the nitroso radicle. In one a boiling acidified solution of the nitrosochloride was saturated with a current of chlorine. In another the solution was made strongly alkaline with sodium hydroxide and boiled. In a third the solution was made alkaline, sodium peroxide added, and boiled. None of these treatments was at all effective.

Wichers, ${ }^{15}$ in his experiments on the separation of rhodium from platinum, had observed the incomplete precipitation of ruthenium when solutions of the nitrosochloride were boiled with a suspension of barium carbonate. He concluded that the solution as prepared really contained a mixture of chloride and nitrosochloride, and that the former compound was hydrolyzed with complete precipitation while the latter precipitated only slightly if at all.

\section{BEHAVIOR OF RUTHENIUM WHEN PRESENT AS AN AMMINE}

A solution of ammonium chlororuthenate which had been made ammoniacal and boiled, then acidified with hydrochloric acid and neutralized with sodium bicarbonate, gave only a small amount of black precipitate. The greater portion of the ruthenium remained in solution, imparting to it a dark color. Such a behavior was to be expected, since the platinum metals are transformed in ammoniacal solution into ammines, some of which are very stable. 


\section{SUMMARY OF RESULTS OBTAINED}

1. Ruthenium, when present as a chloride, can be quantitatively precipitated as a hydrated oxide from a boiling solution having a $\mathrm{pH}$ value of about 6.0. If present as nitrosochloride or as ammine only a slight precipitation occurs.

2. There is a tendency to deflagrate, with accompanying loss of ruthenium, when the hydrated oxide is converted by heat into the anhydrous oxide. This tendency is minimized if the filters contain a small quantity of either ammonium sulphate or ammonium chloride. The quantity of salt retained when the filters and precipitates are washed with a 2.5 per cent solution of either of the salts named appears to be sufficient to overcome the danger of deflagration.

3. The presence in the solution of alkali chlorides, such as potassium chloride, introduces no appreciable error into the determination. The alkali chloride may be completely removed from the precipitate by washing.

4. There is no significant loss of ruthenium on ignition in air, with the full heat of the Tirrill burner, during the time required in the analysis, namely, one hour.

5. The detection of ruthenium in solution is readily accomplished by reaction with thiourea. The limit of sensitivity appears to be 1 part in 100,000 parts of solution.

\section{THE METHOD}

\section{PRECIPITATION}

Use clean unetched beakers. Adjust the volume of the solution so that it contains not more than $0.2 \mathrm{~g}$ of ruthenium in $150 \mathrm{ml}$. If necessary, acidify with hydrochloric acid. If the ruthenium solution has been evaporated with a considerable quantity of alcohol, add $5 \mathrm{ml}$ of freshly prepared chlorine water and boil. In any case, heat the faintly acid solution just to boiling and add a 10 per cent solution of sodium bicarbonate, free from insoluble matter, until a precipitate suddenly coagulates. Add a few drops of brom cresol purple indicator. Then add sufficient bicarbonate solution to produce a faint purple color, boil five to six minutes, and filter immediately. Wipe the inner walls of the beaker and also the glass stirring rod with a small piece of filter paper to remove adhering precipitate. Wash thoroughly with a hot 1 per cent solution of ammonium sulphate. Finally wash three or four times with a cold 2.5 per cent solution of ammonium sulphate.

\section{IGNITION}

Place the filter and precipitate in a porcelain crucible and char the paper somewhat slowly. The dried filter will usually char completely when once it begins to smoke. Ignite the residue to remove all carbonaceous matter.

\section{REDUCTION}

Cover the crucible with a Rose lid, preferably of quartz. Introduce into the crucible a stream of hydrogen, burning from the tip of a Rose delivery tube (a quartz tube is preferred). After five $77886^{\circ}-29-12$ 
minutes remove the burner and a few minutes later extinguish the hydrogen flame by momentarily breaking the current of hydrogen. This is best done by having a section of the rubber delivery tube replaced by a glass tube, one end of which can easily be disconnected. Allow the ruthenium to cool in an atmosphere of hydrogen and weigh as metallic ruthenium.

Acknowledgment is made to Edward Wichers for many helpful suggestions.

Washington, June 14, 1929. 